\title{
ABOUT PROTOBULGARIAN CROSS-SHAPED TEMPLES?
}

\section{Galabina Yosifova, b8d8h8@abv.bg}

National archaeological institute with museum - BAS, Shumen, Bulgaria

\begin{abstract}
The article examines two buildings with a cross-shaped plan, located in Pliska. After the destroying of one of the buildings, the Great Basilica was built on its remains. The report includes all the opinions of researchers about the purpose of the cross-shaped building - a tomb from the early Byzantine period, a protobulgarian pagan temple, a mausoleum of the Bulgarian Khans, a church, a baptistery, a martyrium. Its construction history, superstructure, construction periods, facilities that are functionally related to it, its fate after the adoption of Christianity are examined. A church was built on the foundations of the second crossshaped building. Therefore, her researcher is of the opinion that it was a protobulgarian temple. Most archaeologists believe that only the buildings with a plan of inscribed quadrilaterals were protobulgarian pagan temples and in their works do not mention this building at all and do not comment on the possibility that it was a pagan temple. R. Rashev reminded us of this forgotten monument. Other archaeologists also believe that the two cross-shaped buildings were probably pagan temples and formed a new group of cross-shaped temples in addition to the group of temples with a plan consisting of inscribed quadrilaterals.
\end{abstract}

Keywords: protobulgarian cross-shaped temples, cross-shaped building, Pliska, Great Basilica, church № 3

\section{ЗА ПРАБЪАГАРСКИТЕ} КРЪСТОВИАНИ ХРАМОВЕ?

\section{Гь^ьбина Йосифрова, b8d8h8@abv.bg}

Национален археологически институт с музей - БАН, Шумен, България

Резюме: Предмет на статията са Аве сгради с крьстовиден план, намиращи се в Плиска. СлеА разрушаването на елната сграла вьрху нейните останки е построена Голямата базилика. Разгледани са строителната история на крьстовинната сграда, наАстройката й, строителните периоди, предназначението ѝ спореА отАелните изслеАователи - гробница от ранновизантийския периоА, 
прабългарски езически храм, мавзолей на българските канове, църква, кръщелна или мартирий, съоръженията, които са функционално свързани с нея, съдбата ѝ слеА приемането на християнството.Върху основите на втората кръстовиАна сграда е изградена църква № 3. Затова нейният проучвател е на мнение, че тя е била прабългарски храм. Повечето археолози смятат, че само постройките с план от вписани четириъґлници са били прабългарски езически светилища и в своите разработки въобще не споменават за тази сграла, и не коментират възможността тя $\Delta а$ е представлявала капище. Р. Рашев ни припомни този позабравен паметник. Аруги археолози обаче считат, че вероятно Авете кръстовиАни сграли са фоункционирали като капища и образуват нова група светилища с крьстовиден план освен групата от храмове с п^ан, състоящ се от вписани четириъґлници.

КАючови Ауми: прабългарски крьстовиАни храмове,

крьстовиАна сграда, Плиска, Голямата бази^ика, цьрква № 3

Предмет на статията са две сграли с кръстовиден план, намиращи се в Плиска - пол Голямата базилика и цьрква № 3. Разгледани са тяхната налстройка, строителните периоли, предназначението им, съоръженията, които са функционално свързани с тях, сълбата им слеА приемането на християнството. Мненията относно функциите на пьрвата крьстовиАна сграда са разнопосочни - гробница от ранновизантийския периол, прабългарски езически храм, мавзолей на българските канове, цьрква, кръщелна, мартирий. Проучвателят на втората сграла с кръстовилен план е на мнение, че тя вероятно е била прабългарско светилище. Повечето археолози смятат, че само сгралите с план от вписани четириъґљници са представлявали прабългарски храмове и в своите разработки въобще не споменават за тази сграла, и не коментират възможността тя да е представлявала капище. Р. Рашев ни припомни този позабравен паметник. ПовоА за написването на статията е позицията на няколко археолози от послеАните гоАини, че вероятно Авете кръстовиАни сгради преАставляват прабългарски храмове, както и новите мнения относно орункциите на сградата пол базиликата.

\section{Археологически контекст на кръстовиАната сграда поА Голямата базимика}

ПреАи изгражАането на Голямата базилика на терена около нея е съществувало поселение, датиращо от края на VIII - пьрвата половина на IX в. То се е състояло от вкопани землянки. 
През 1973 г. Т. Тотев в източната част на средния кораб на базиликата проучва монументална постройка с крьстовиден план (Totev, 1984, рр. 160-165). Близо Ао нея са разположени каменни саркофази на висши прабългарски военачалници, а непосрелствено Ао стилобата на южния кораб на базиликата се намира Аьлбок к^аленец, предхожАащ изграждането на последната (Boyadzhiev, 1986, р. 28). Крьстовидната сграАа, клаленецьт, некропольт, няколко леки Аьрвени постройки са би^и заградени с ограАа, чиито главен вхоА е би^ от Юг, в еАна Ос С южното рамо на сградата като до него е водила каменна алея (фриг. 1) (Georgiev, 1993, pр. 90-91).

\section{Разположение, планировка, размери и строителна техника на кръстовиАната сграАа}

П^аньт на крьстовиАната сграАа се състоИ от Аве еАнакво АьАГИ правоъгьлни тела, които се пресичат поА прав ьгьл и образуват равнораменен грьцки крьст сьс своболно издаващи се рамена като тесните страни на крьстните рамена представляват сегменти от окрьжност. Сградата е с размери 15,50 × 15,50 м. От постройката са запазени хоросановите полАожки на каменните основи. На Аьлбочина 11,20 м пол равнището на пола на базиликата в зАравия терен са отлети хоросановите полАожки с пилоти. Основите са били изградени от наймалко Ава реда варовикови блокове с размери 0,40-0,50 М, но нито еАин блок не е запазен in situ. Вътре в постройката и $А$ нея са разположени Няколко хоросанови поАложки с различни размери за основи на стьлбове и стени, вкопани с 0,40 м по-плитко от поАложката на основите (фриг. 2) (Totev, 1984, p. 164-166), (Boyadzhiev, 1986, p. 28), (Boyadzhiev, 2008, p. 116), (Georgiev, 1993, p.41).

\section{НаАстройка на храма и строителни периоАи}

Спореа Ст. БояАжиев и Я. Василев сградата е имала Ава строителни периола, а спореА П. Георгиев - три. Функционалното й предназначение през пьрвия строителен периол е спорно. П. Георгиев счита, че тя е била мартирий на Енравота, а Ст. Боялжиев - мавзолей на кан Тервел. През втория строителен периол сградата е преустроена в цьрква (Boyadzhiev, 1986, р. 30-31), (Boyadzhiev, 2008, p. 112), (Georgiev, 1993, p. 45-46), (Vasilev, 2009). 


\section{Първи строителен периоА}

Ст. Боялжиев, П. Георгиев и Я. Василев правят реконструкции на паметника (фриг. 3). Сгралата е имала Ава етажа като спореА Ст. БояАжиев първият е би^ частично вкопан в земялта. Основите, образуващи затволрен кваАрат точно в пресечището на крьстните рамена, свилетелстват за това, че нал тях се е излигала налстройка. В югозапалното межАурамие е разположена пол^ожка, конструктивно свързана със запалното рамо, успоредна на южното рамо. МежАу нея и последното вероятно е била развита масивна каменна низходяща

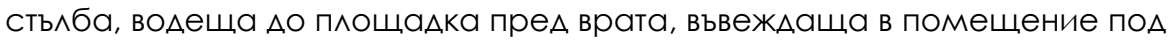
запалното крьстно рамо. В източната стена на това помещение е разположена врата, волеща кьм главното помещение в пресечището на крьстните рамена. От него чрез по-тесни врати се е Аостигало Ао крьстните рамена, в които са били разположени саркофразите на канското семейство. Наличието на подземния етаж се Аоказва от основите, очертаващи габарита на подкуполния квалрат. НаА тях в етажа не се издигат стени. Изчисленията показват, че Аьлбочината на полземието е била око^о 1 м, колкото е и Аьлбочината на която ^ежат хоросановите поАложки на основите на сградата. НаА земята е изпьква^ цокьлният етаж, носещ преАставителната част на сградата. Постройката притежава всички елементи, характерни за монументалните гробници. Кьм сьщинската погребална камера, сьстояща се от обособено кваАратно помещение, воли стьлбище, разположено от Аясната страна на главната композиционна ос на зАанието. Широка външна стьлба извежАа $А$ ГАавния вхол, разположен на запалната фраса $\triangle \mathrm{a}$, въвежАащ в представителния етаж, предназначен за отслужване на заупокойни молитви и вьзхвала на погребаната в криптата канска особа. В по-кьсна публикация Ст. Боялжиев смята, че входьт кьм етажа е бил разположен на южната фрасала и е въвежАал в южното крьстно рамо (Totev, 1984, р. 166), (Boyadzhiev, 1986, p. 30), (Boyadzhiev, 2008, p. 108, 116-117, fig. 133).

Я. Василев счита, че сградата е била Авуетажна, но пьрвият етаж не е бил вкопан, а подьт му е бил наравно с околния терен. Поради изважАането на квалрите от основите при разрушаването на сгралата не е сигурно кьАе са били разположени входовете кьм пьрвия иे етаж. 
ГАавният вхоА Кьм него вероятно се е намирал на южната стена на южното рамо, кьлето е изгралена постройка Г, служеща за прелверие към вхола. През пьрвия строителен периол е възможно вхо Аове към пьрвия етаж $\Delta$ а са съществували и на четирите рамене на зАанието за $\triangle а$ бъАе централното му помещение Аостьпно и виАимо от всички страни. При стьлбището в югозапалното межАурамие не са открити слеАи от вкопаване, поради което то не би могло Аа воАи наАолу, към предполагаем полувкопан етаж, а само нагоре кьм втория етаж на заанието (Vasilev, 2009).

СпореА П. Георгиев стьлбата в югозапалното междурамие е била възхояяща. Същинската част на храма е стьпвала върху висок

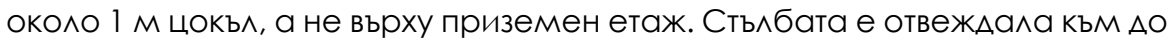
Ава отАелни вхоАа - в запаАното и южното рамо. Съществуването на

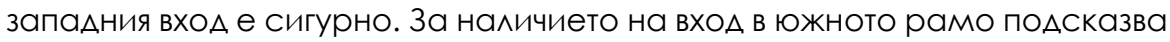
разположеният в него фуннамент 1, който вероятно е служел за постамент на масивен саркофраг. Сьставьт на хоросана и полможката на орундамента са аналогични с тези от поАложките за основи на сградата и фрунАаментьт принаАлежи към пьрвия й строителен периол. По-високото му ниво и положението му в помещението, изключват възможността той $а$ а е свьрзан с конструкцията на постройката. Саркофрагът се е намирал в приземната част на сградата, а покритието му е било на елно ниво с пола на помещението нал него. Приземието, запьлнено с насип, е било ниско и пракитически неизползваемо (Georgiev, 1993, рр. 47-48). ФунАамент 1 е построен на това място слеА разрушаването на крьстовиАната сграла и слеА изгражАането на източния стилобат на базиликата. Най-вероятно хоросаньт от фуунАамент 1 е остатьк от бъркало за хоросан, използван при строежа на базиликата (Boyadzhiev, 2008, р. 111). Ст. БояАжиев счита, че сградата се е изАигала вьв фрормата на свободно изявен крьст сьс заоблени рамена, които са се извисявали на еднаква височина. Порали дебелите стени крьстните рамена вероятно са били покрити с полуцилинАрични сводове, а наА пресечището на рамената се е извисявал цилиндричен барабан, увенчан с купол. Полкуполният квалрат е с размери 4,60 × 4,60 м (Boyadzhiev, 2008, p. 110, p. 116), (Totev, 1984, p. 166). 
Най-вероятно крьстните рамена са били заоблени само на нивото на пьрвия си етаж, Аокато фрасалите на втория етаж са били изпьлнени слеА мальк отстьп и са преАставлявали П-образни тела. Вторият етаж с купола е бил висок вероятно около 22-23 м. а сгралата заелно с първия етаж - около 26-28 м (Vasilev, 2009).

\section{Втори строителен периоА}

Ст. Боялжиев прьв Аостига до заключението, че полложките за фундаменти на стьлбове и зиАове, които не са конструктивно свързани със сградата, са част от по-късни преустройства и не принаАлежат към пьрвичния иे план. През втория строителен периол межАу рамената на крьстовиАната сграда са изАигнати кваАратни помещения. От тях са се съхранили следи от хоросановата пол^ожка (Boyadzhiev, 1986, р. 31), (Georgiev, 1993, p. 45).

ФунАамент 3 е Аобавен през втория строителен период като е затварял помещението в югозапанното междурамие. Симетрично помещение е имало и в северозапалното междурамие, част от което е фрундамент 4. Северният му край, както и северният зид на помещението са унищожени при трасирането на основите на базиликата. Част от фрундаментите на помещенията в източните межАурамия попаАат поА основите на последната и са разрушени в много голяма степен при строежа иे. Преустройството на крьстовиАната сграАа в постройка С крьстовиАен п^ан, вписан в кваАрат, показва, че тя е била превьрната в крьстокуполна цьрква (Boyadzhiev, 1986, р. 31), (Georgiev, 1993, p. 45-46, рр. 51-52). Източната АьговиАна стена на източното крьстно рамо е била съборена, за Аа се пристрои Ао нея сложен олтар от цариграАски тип, отАелен от наоса с олтарна преграда. Олтарьт е включвал фуундаменти 2, 10 и 11, вьрху които са изгралени три апсиди (Boyadzhiev, 1986, р. 31), (Boyadzhiev, 2008, р. 112). П. Георгиев се съмнява в наличието на преАапсиАно пространство и странични апсиАи. Той смята, че среАната апсила е Аобавена Аопьлнително, но през пьрвия строителен периол (Georgiev, 1993, рр. 50-53). В запалното межАурамие е изгрален притвор. В межАинлните стени, разделящи крьстните рамена, били пробити шилроки отвори, за да наблюдават богомолците извършваните преА олтара обреди. 
При направените преустройства носещите стени и сводовете се пропукали. ФунАаменти 5 и 6 представляват контрафрорси и изглежАа са поААьржали пропукалия се своА наА запаАното рамо (Boyadzhiev, 1986, рр. 31-32). Няма Аанни за пропуквания в стените. Наличието на помещения в източните междурамия не е Аоказано, тъй като фундаментите 7, 8, 10 и 11 не се Аопират пряко $А$ основите на крьстовиАната сграда и не са разположени правилно спрямо тях. В запалните межАурамия зидовете вьрху фундаменти 3 и 4 са оформяли Аве нови помещения. Наличието им Аоказва преустройството на сградата в цьрква. ФунАамент 1 е Аолепен АО гАавния южен вхоА, който изглежАа е фуункционирал през пьрвия строителен периоА. Разполагането на фундамента Ао южния вхол свилетелства за това, че вероятно изгражАането му е станало при преустройството на сградата в църква, при което ГАавният й вхоА е изместен в запаАното кръстно рамо. ФунАамент 1 вероятно е преАставлявал основа на вьтрешно Г-образно стьлбище, волещо кьм втория етаж на зАанието. То е трябвало $а а$ замести изоставеното при преустройството в църква пьрвично външно стьлбище, вьрху което е било изгралено помещението в югозапалното межлурамие (Vasilev, 2009).

Вероятно помещенията от пьрвия строителен периол на сградата са запазили пьрвоначалната си конструкция, а покривът на новите помещения е би^ по-нисък от покрива на старите (Georgiev, 1993, р. 52). При разрушаването на крьстовидната сграда каменните блокове от основи иे са били извалени, за $\Delta \mathrm{a}$ се преупотребят в основите на базиликата (Boyadzhiev, 1986, р. 32).

\section{Трети строителен периоА?}

ФунАаменти 10 и 11 вероятно са изгралени през трети строителен периол, сьвременен на базиликата, когато крьстовидната сграда се е използвала частично. Те са разположени по-високо в сравнение с фрунАамент 2 и не са офрормяли страничните апсиАи както преАполага Ст. БояАжиев. ПоА централната част на олтара на базиликата П. Георгиев разкрива изкоп, разположен в рамките на основите на източното крьстно рамо, и Аопуска, че там е било изградено вкопано помещение вероятно представляващо крипта (Georgiev, 1993, рр. 52-54). 


\section{Стратиграфия на терена около кръстовиАната сграАа}

П^астьт с материалите от селището лежи върху необитаван

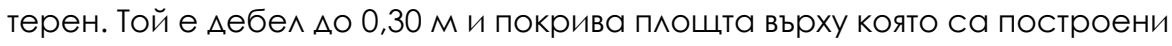
манастира и базиликата. П. Георгиев смята, че селището е възникнало в края на VIII - пьрвата половина на IX в. ПоА строителното ниво на кръстовидната сграла е разположен, Аебел 0,10-0,15 м, слой от тъмночерна пръст с материали от селището, които се откриват и наА строителното ниво в слой от смесена жълто-черна пръст, вероятно от изкопите за основите на сградата. Част от тези материали са съвременни на фонкционирането на зАанието и са еАнакви с тези в п^аста на селището. Мартирият възниква на територията на селището като то проАь^жава $А$ а съществува $\Delta$ о неговата ограда в северна и източна посока. Жителите на селището може би участват в изгражАането и обслужването на мартирия. Горната граница на живота в селището е залагането на основите на базиликата по време на матинската мисия межАу 866 и 869 г. МежАу хоросановите поАложки на кръстовиАната постройка има 1-2 см черна прьст с въгленчета - тя е била опожарена. Срокът межАу премахването на квалрите иे и залагането на основите на базиликата е бил много кратьк (Georgiev, 1993, p. 9, p. 36, pp. 55-56, pp. 96-97).

\section{Кладенец}

К^аАенецьт се намира на 7-8 м Югозапално от крьстовиАната сграла. Разположен е в средата на южния кораб на базиликата и спореА Шкорпи^ к^аленецьт и цьрквата са синхронни, а той вероятно е свързан с нейната кръщелна (Georgiev, 1993, pр. 75-76), (Boyadzhiev, 2008, р. 119). Ст. Ваклинов стига до заключението, че клаленецьт е изграден преди базиликата. Съществува функционална връзка межлу клаленеца, селището, крьстовидната сграда и базиликата. П. Георгиев смята, че периолите, през които е фрункционира^ к^аленецьт, са три - периола на съществуване на селището, на мартирия с некропола, и на базиликата. Вероятно клаленецьт е заловолявал нужАите от питейна вода както на селището, така и на околната територия от Външния граА на Плиска (Georgiev, 1993, pp. 76-83). 
ГЪАЪБИНА ЙОСИФОВА

\section{Функционално преАназначение и Аатировка на сградата Тезата за кански мавзолей}

КрьстовиАната сграда не е изАигната върху останките на селище от VIII в. Кан Терве^ издига своя мавзолей върху празен терен. К^аленецьт също е построен от Терве^ като светената вода е използвана в ритуалите в памет на кана (Boyadzhiev, 2008, р. 108, рр. 119-120). Мавзолеят е разположен във Външния грал в среАа, къАето е отАавана почит към Тангра и кълето впослледствие се развива аристократичен некропол (Boyadzhiev, 1986, р. 32). Мавзолеят се превръща в място за пок^онение и последно жилище и на други канове. Може би в него е погребан кан Омуртаг, тъй като името му е изписано върху капака на саркофрага на болярина Отурдач (Boyadzhiev, 2008, р. 119), (Ovcharov, 2005, pр. 204-206).

Свещеният характер на канската институция, почитта към мьртвите и предците подкрепят тезата на Ст. Боялжиев, че сградата е представлявала мавзолей на бьлгарските канове. Той е имал важно значение за религиозния живот на прабългарите. Вероятно поклонението

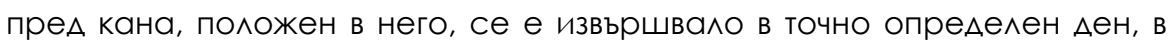
който живият влалетел се е явявал преА поданиците си и е рьковоле^ процесията до мавзолея (Teofilov, 1993, р. 77). Най-вероятно през петлесетте голини на IX в. кан Борис е построи^ гробница за себе си и за семейството си. Заенно с основното си предназначение на влалетелски мавзолей, може би крьстовиАната сграда е изпьлнявала и фрункциите на поминален храм, посветен на култа към преАците и към небесните сили. В него вероятно е бил разположен олтар върху който е горя^ свещеният огън на владетеля. ИзглежАа в района на кръстовиАната постройка кан Борис се е покрьстил. Превърнатият в цьрква мавзолей, порали неголемите си размери се оказал неподходящ за столична катедрала, зарали което неговото преустройство може би е останало незавършено и той би^ разрушен. В северния анекс на базиликата е изграден гроб-олтар, в който вероятно е бил погребан княз Борис - на пьрвоначално предвиленото място, но не в мавзолея, а в гробничен параклис към базиликата (Vasilev, 2009). Р. Рашев счита, че тъй като във вътрешността на сградата няма Аанни за наличието на крипта, тезата за кански мавзолей, трябва $а$ а се изостави (Rashev, 2008, р. 99). 


\section{Тезата за прабългарски храм}

КрьстовиАната сграда е била езически храм и е функционирала еАновременно с клаленеца. Заоблените крьстни рамена, ориентирани прави^но по посоките на света, се вписват в правилен крьг и Ст. Ваклинов сравнява постройката с тралиционното номалско жилище - юртата. За това, че сградата е съществувала през пьрвата половина на IX в. свидетелстват намерените при разкопките на некропола и базиликата прабългарски налписи от времето на Крум и Омуртаг. Голямата базилика е издигната на място, свързано с оорициалните езически култове. Преди построяването й, капището било унищожено, а олтарната иे част е изградена върху останките му (Vaklinov, 1974, p. 35), (Vaklinov, 1977, pр. 169-170), (Vaklinov and Shtereva, 1993, р. 44). С основание Ст. Ваклинов Аири аналози на крьстовиАната сграда среА монголските юртообразни храмове (Popkonstantinov, 2005, р. 26). Колоните с налписи от езическия периол в базиликата може $А$ са използвани в предполагаемия езически храм или около него, но капище с крьстовиАен план не е открито нито в Аругите аули, нито в култовия център Малара. По своята строителна техника - кваАри, пилоти и хоросан със счукана тухла - постройката принаАлежи към сградите от послеАните етапи на строителство слеА пожара в Плиска (Rashev, 2008, р. 99).

В полкрепа на тезата за езически храм се изказват и В. Бешевлиев и Ст. Стани^ов. ИзглежАа капището е било посветено на култа към Тангра. Обслужвало е обикновеното население на столицата и на селището, сред което е изградено. Може би ритуалните Аействия не са изисквали всички вярващи Аа присьстват в храма. Наземната му част вероятно е преАставлявала голям олтар, а народьт е стоял на открито, наблюАавайки ритуалите, извьршвани в него. Не е било възможно $а$ се построи храм, който Аа побере околното население, а и едва ^и е било необходимо (Beshevliev, 1981, p. 79), (Stanilov, 1982, р. 230).

Порали плана на сградата Т. Теофилов, П. Георгиев и Ст. Михайлов отхвърлят възможността постройката $А$ е изпьлнявала функциите на прабългарски храм, тъй като схемата иे се различава от определяните като капища сгради с п^ан от вписани четириъгљниици, но в арало-каспийския район К. Попконстантинов открива езически 
светилища, посветени на огъня, които представляват аналози както на прабългарските светилища, състоящи се от вписани четириъгьлници, така и на крьстовиАната сграда. В Байтинския комплекс в Казахстан са проучени храмове, чиято схема е много близка $А$ плана на крьстовиАната постройка. Окръжността, квалратьт, крьстьт символизират модела на света - небето, земята, световните посоки, центьра. Байтинският храм е сходен със зороастрийските храмове на огъня. Те са покрити с купол, четири врати, разположени по световните посоКИ, водят Кьм вътрешността им, а в среАата им е изгрален жертвеник (Teofilov, 1993, p. 76), (Georgiev, 1993, p. 58), (Mihailov, 1995, p. 47), (Popkonstantinov, 2005, рр. 26-28). КрьстовиАната сграда се намира в североизточната част на ограденото пространство, а в неговия центьр е разположен клаленецьт. Възможно е тя $\Delta а$ е изгралена вторично, а комплексьт да е офрормен около к^аленеца. През езическия периол би мог^о в заградената площ $а$ е практикуван някакъв култ Към водата (Hrisimov, 2018, p. 87).

\section{Тезата за раннохристиянска гробница}

П^ановата схема на постройката е характерна за V-VII в., когато почти всички сгради от типа "Свободен кръст" имат мемориален гробничен характер (Totev, 1984, р. 169). Някои автори смятат, че типьт „Свободен кръст" не се употребява слеА VII в. и затова преАлагат аналози от ранновизантийската епоха (Georgiev, 1993, р. 58). Най-вероятно сградата е била раннохристиянска гробница с пет самостоятелно обособени помещения, във всяко еАНо от коИто е ИМа^о по еАИН саркофраг на заслужи^ приживе покойник. ИзглежАа откритите пет саркофрага при Голямата базилика, вторично употребени от българите през IX в., Аа произхожАат от крьстовидна постройка (Mihailov, 1995, p. 48). Кьм Аатиране на послеАната през раннохристиянската епоха насочва и мнението на Ст. Михайлов, че през IX-X в. не съществува тралиция Аа се изграждат мартирии или гробници като самостоятелни архитектурни паметници (Milchev, 1995, р. 53).

\section{Тезата за мартирий}

Извън градовете и изолирани от Аруги християнски строежи се строят мартирии, изградени наА гробове или места, свързани с 
подвизите на светци и мъченици. П. Георгиев допуска, че в селището е имало тайна християнска община и там е екзекутиран Енравота. Крьстовидната сграда е изградена най-Късно в пьрвите гоАИни от управлението на княз Борис и най-вероятно е преАстав^явала мартирий на Енравота. За мартириалния характер на постройката свилетелства разположеният в южното й рамо постамент за саркофаг. Пристрояване на помещения в междурамията на сгради от типа „своболен крьст“ е типично за еволюцията им към вписан четириъгьлник в крьст. Имаме Аанни за гроб само в южното рамо на сградата, но вероятно междурамията са изгралени с илеята да изпьлняват същите фрунцкии. С изгражАането на апсидата и притвора сградата се преврьща в цьрква, но запазва гробничния си характер като гробовете са разположени в междурамията, а не както е било през пьрвия строителен периол - в крьстните рамена. Освен мартирий, сгралата вероятно е представлявала и мавзолей на членовете на управляващата Аинастия. В рамките на територията на мартириите много често се изгражда к^аленец, почитан като свещен водоизточник. При опожаряването и разрушаването на мартирия през 865 г. по време на антихристиянския бунт върху клаленеца също са нанесени поражения, но той продьлжава Аа фрункционира през цялото съществуване на базиликата (Georgiev, 1993, р. 57, рр. 63-64, рр. 76-83, р. 123, р. 132). Връзката межАу Енравота и крьстовидната сграда е по-скоро хипотетична, отколкото Аоказана. Ао Аоказването й проблемите около принца и постройката е необхолимо да се разглежлат поотлелно. Нямаме Аанни в Бьлгария $а$ а е съществувала традиция $\Delta а$ се строят мартирии. Теофилакт Охридски, описва събитията, свързани с Енравота, три века слеА смъртта на последния. Освен неговото произведение, нямаме никакви Аруги Аанни за почитането и канонизирането на Енравота. Той е посечен, защото вероятно е организирал бунт срещу Маламир, целящ свалянето му от престола, а не по религиозни причини. Не може категорично $\Delta а$ се смята, че е умрял като мъченик (Hrisimov, 2018, pp. 81-85), (Tsanev, 1998, pp. 162-164), (Doncheva-Petkova, 1995, p. 196).

Повече са доказателствата в полкрепа на тезата за християнския характер на сградата отколкото за езическия иे характер. 
Най-Аобре е аргументирано мнението за интерпретирането й като мартирий, преустроен в цьрква. Много малка обаче е вероятността преди покрьстването канът $\Delta a$ Аопусне $а$ б бъле изгрален мартирия и той Аа съществува 10 голини преди офрициалния акт на християнизацията на Аьржавата (Doncheva-Petkova, 1995, p. 196), (Rashev, 2008, p. 99). C^eА VII в. във Византия не се изграждат мартирии и затова не могат $А$ бъ бат посочени синхронни на крьстовидната сгра $А$ мартирии, които $\Delta a$ послужат за нейни аналози. Характерният й п^ан - равнораменен крьст - е типичен за теофаническите мартирии, но като възпоменателни съорьжения те не предполагат наличие на тяло на почитания мъченик, което противоречи на хипотезата на П. Георгиев за полагане на тялото на Енравота във вьтрешността на сградата (Hrisimov, 2018, р. 88). Аристократичният некропол, вьзникнал в началото на VIII в. около мавзолея, изкАючва възможността на същото място $а$ а е изграден мартирий в средата на IX в. (Boyadzhiev, 2008, р. 119).

\section{Тезата за църква и кръщелна}

Порали плана на сградата Т. Тотев я определя като най-ранната черква, изАигната слеА покрьстването и смята, че е преАставлявала църква от типа „Свободен крьст“ (Totev, 1984, р. 165, р. 169).А. Ми^чев и Н. Чанева-Аечевска също смятат, че сградата е била цьрква, но А. Милчев я $\Delta$ атира най-кьсно в началото на VI в. (Milchev, 1995, р. 52), а Н. ЧаневаАечевска смята, че е изградена след покрьстването (ChanevaDechevska, 1984, р. 19).По време на покрьстването мартирият е превърнат в баптистерий, а построеният от южната му страна портик постройка Г, отворен на запал към клаленеца-аязмо, изглежАа е бил предназначен за оглашените (Georgiev, 1993, р. 134). СпореА Ц. Цанев крьстовиАната сграла е била крьщелна, а слеА това е преустроена в цьрква. За това свидетелства планьт й - раменете й са заоблени и се сьздава представа за крьст, вписан в крьг. Крьщелната е възникнала в 853 г. и^и непосредствено слеА това. Преустройството в цьрква вероятно е станало през 864 г. във връзка с покрьстването на Борис, а унищожаването на сградата през 866 г. от разбунтувалите се боляри (Tsanev, 1998, pp. 164-165). 
Защо е нужно Борис да изгражла кръщелна в 853 г., а самият той $\Delta$ с се покръсти Аесетилетие по-късно? Кръщелна е нужна в 864 г., а тогава е преустроена в цьрква. Не е възможно пьрвоначалната крьстовидна сграда $\Delta а$ е представлявала кръщелна, тъй като самостоятелно Аействащите кръщелни не се нужАаят от Аопьлнително пристрояване на олтари, защото те са предвидени да изпьлняват предназначението си самостоятелно, без съчетанието им с базилика. При разкопките около кръстовиАната сграда не се попаАа на останки от базилика, съвременна на послелната. Превръщането на канския мавзолей в християнска култова сграда вероятно е станало по времето на първото пребиваване на византийското Ауховенство в България, т.е. Ао 866 голина. Може би преустроената сграла е служила за кръщелна на боилите, полкрепящи Борис. Неустойчивата почва в Плиска и преправките на зАанието причинили непоправими щети, наложили събарянето на превьрнатия в кръщелна мавзолей и издигането на негово място на Голямата базилика (Boyadzhiev, 1986, р. 32).

Ст. Михай^ов отнася крьстовиАната сграда към ранновизантийската епоха, но тереньт около сградата не е обитаван по това време. Същото се отнася и за датировката на Ст. Боялжиев в нача^ото на VIII в. ПоАложките за основите на сградата са изгралени от хоросан нал реА от Аребни камъни и крьгли пилоти, което е характерно за строежите в Плиска от пьрвата половина или средата на IX в., а не за началото на VIII в. Ст. Боялжиев Аоказва сложната строителна история на сградата. Трудно е $а$ а се приеме, че тя, постройките и съоръженията около нея са фонкционирали само 2-3 голини. Вероятно тя е фрункционирала поне десетина голина и е изгралена най-късно в пьрвите голини от управлението на Борис. ИзгражАането на крипта с трибуна в олтара на базиликата е характерно за сренновековните цьркви в Запална Европа и е пореАното Аоказателство, че кръстовиАната сграда е унищожена в началните голини слеА покръстването. СлеАите от пожар свилетелстват за насилственото й унищожаване най-вероятно при антихристиянски бунт от 866 г. (Georgiev, 1993, рр. 56-57). Кулатапропилей преА атрия и еАиничният олтар на базиликата не Аоказват, че тя е изгралена по време на пребиваване на ^атинската мисия. 
Обвьрзването на разрушаването на крьстовидната сграда с периола на пребиваване на мисията е само спорно предположение, както и тезата за унищожаването на сградата при бунта на боилите (Vasilev, 2009). Спорел мен сгралата е представлявала капище и е изгралена слеА 811 г. вероятно от кан Омуртаг. Тя е претърпяла преустройства, които не могат $а$ а се вместят в краткия периоА от възцаряването на Борис Ао началните голини на християнизацията, както смятат П. Георгиев и Ц. Цанев. Постройката не е била преустройвана в цьрква. ФунАаментите в източните межАурамия вероятно са свързани с базиликата и не служат за стени на вторично изградени помещения. В запалните межАурамия вторично са изгралени помещения, в които вероятно са били разположени каменни или метални фриали за светената вода. Преминавайки през вхола на запалната фрасала, богомолецьт се е озовавал в запалното крьстно рамо, от къАето през отвори в северната и южната му стени, е Аостигал Ао фриалите в новоизградените помещения (фриг. 4 а). Ако сьщинската част на храма е била Аостьпна само за влалетеля и свещенослужителите, то вратата към помещението в югозапалното междурамие, е била разположена на южната или запалната му стена, а вратата на помещението в северозапалното междурамие - на северната или запалната му стена, за $\Delta$ а черпят богомолците безпрепятствено от светената во $А$, без $\Delta$ a влизат в същинската част на храма (фриг. 4 б).

\section{Стралата под църква № 3}

Сгралата се намира на около 2 км североизточно от Вътрешния граА и има три строителни периода. Проучена е през 1945 г. от Ст. Михайлов. През пьрвия строителен периол тя е преАставлявала правоьгьна постройка на чиито северна, южна и западни стени, от вътрешната страна, са били разположени по еАна П-образна ниша, изАаващи се съответно пред северната, южната и западната фрасали (фриг. 5). От най-ранната постройка са оцелели само основите и спореА разкопвачьт не е сигурно Аали среАните стени на нишите са би^и п^ътно изгралени или нишите са представлявали портали, в които са били поместени вхоАОве. По-вероятно е стените на нишите Аа са били пльтни, а

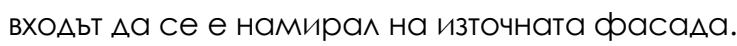


За наличието на вхоА от изток поАСказва и правоъгънното помещение, в източната част на сградата, което вероятно е било предверие. През втория строителен периол върху основите на по-ранната постройка е изгралена еннокорабна цьрква, Аьлга 8 м и широка 4,50 м. Притвор мипсва. През третия строителен периол $А$ южната стена на цьрквата е построено правоъгьлно помещение, което е преАстав^ява^о семейна гробница. Порали малките си размери, цьрквата е обслужвала ограничен брой хора и вероятно е имала частен харакер, като впоследствие е превьрната в семейна гробнична цьрква. СпореА проучвателя вероятно най-старата сграда е била капище, ориентирано запал-изток, с вход от изток. При проучването не са намерени нахолки, които Аа осветлят датата на съграждане на цьрквата. Ако по-старата сграда е била капище, то вероятно цьрквата е изгралена скоро слеА покрьстването през втората половина на IX и^и началото на X в. (Mihailov, 1995, pp. 197-201).

Ст. Михайлов пише, че по-ранната постройка и цьрквата са изградени от ^омени камъни и ка^, но от фотографиияа, направена при paзкопките (Mihailov, 1995, р. 199, fig. 26), е виАно, че основите на пьрвата постройка са гралени от прави^но Аялани блокове. С^еА приемането на християнството в ПАиска се изгражАат преАимно сграАи от Аомен камък, споен с ка^ (Rashev, 2008, рр. 98-99). Основите на най-ранната сграла са много по-Аьлбоки от основите на гробничната пристройка (Mihailov, 1995, р. 199), което показва, че върху тях са стьпвали стени, изгралени от квалри, а не от ^омен камък.

Пьрвоначалната сграда вероятно представлява нов тип езически храм, съставен от централно крьстовилно помещение с три ниши и предверие откъм изток (Rashev, 2008, р. 99). Крьстовидната сграла и сградата пол цьрква № 3 вероятно са били капища и могат $\Delta а$ се обеАинят в еАна група крьстовиАни прабългарски храмове. Като техен аналог може да се посочи крьстокуполния храм на Ситалк I в СогА в Средна Азия. Може би в крьстовидните храмове е почитан свещен обект, който е трябвало $а$ бъде виАим от всички страни, като вероятно не е преАставлява^ ило^ или олтар за жертвоприношения, а по-скоро е би^ обект, изглежАащ еАнакво отвреА - например горящ свещен огън 
(Chobanov, 2014, pр. 70-71) (Vasilev, 2009). Различията в начина на гралеж на пьрвоначалната постройка и цьрква № 3 полсказват за наличието на Ава строителни периола. По-ранната постройка не би могла $А$ а e църква, тъй като ориентацията иे е противоположна спрямо ориентацията на цьрквата. Планьт на по-ранната сграАа, кваАровият гралеж и Аебелината на стените (0,80 м - измерено от плана) свилетелстват за това, че вьпреки малките си размери, тя е имала специално предназначение. Гробничната пристройка, Аолепена Ао нея, полсказва, че тя също би могла да има мемориален характер. Правоъгьнното помещение в източната част на сградата, може би е служило за гробница на знатна особа. Върху олтар, от който не са запазени следи, разположен в средата на наоса, вероятно е горя^ свещен огън в чест на починалия. Тъй като нямаме Аанни прабългарите $а$ с са изгражлали мавзолеи, то по-вероятно е сградата $\Delta$ а е фрункционирала като езическо светилище. Може би в правоьгьлното помещение от изток богомолците са оставяли Ааровете за храма. Вероятно в него са били разположени и фриалите сьс светена вола, а в центьра на наоса е горял свещеният огън.

$* * *$

Всяка еАна от възникналите тези за фрункционалното преАназначение на крьстовинната сграла пол базиликата обяснява в $\Delta$ алена степен нейното устройството. Р. Рашев поставя на $\Delta$ невен реА въпроса за съществуването на прабългарски крьстовиАни храмове. Я Василев полробно разглежАа възникналия казус. СлеА като през последните стотина гоАина толкова много се е изписало за прабългарските светилища, е реАно изслеАователите, занимаващи се с тематиката, в своите трудове поне да споменат за съществуването на тезата за кръстовиден храм и Аа я коментират. С оглеА на възникналите нови мнения през последните гоАини, мисля, че темата е актуална и в близко бълеще ще се открият още аналози слеА зороастрийските храмове на крьстовилните прабългарски постройки, които ще са в подкрепа на тезата за функционирането им като капища. 


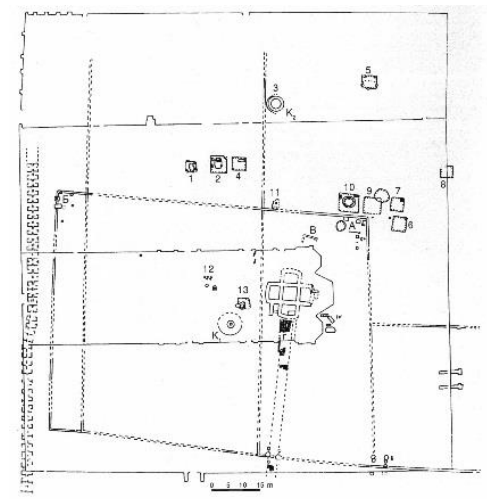

Фиг. 1 Общ план на селището и мартирия поА Голямата базилика и манастира около нея: 1-13 - жилища от селището; К1 - клаАенец-аязмо на мартирия; А - Г постройки в рамките на мартирия; IV - саркофаг № 4 от некропола (Georgiev and Vitlyanov, 2001, p. 13, fig. 4)

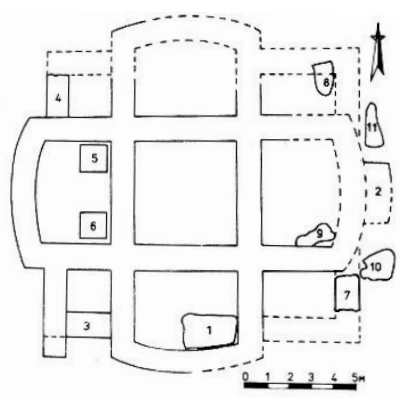

Фиг. 2 Местоположение на фунаवментите вън и вътре в кръстоваината сграАа поА Голямата базилика (Georgiev, 1993, p. 44, fig. 35)

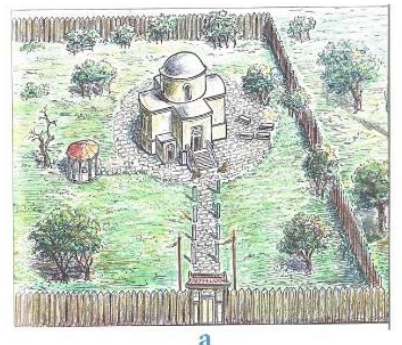

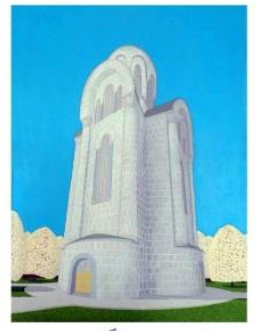

6

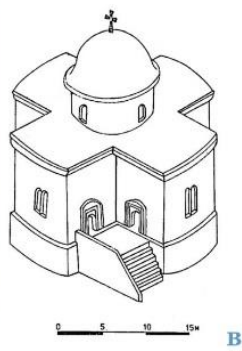

B

Фиг. 3 Реконструкции на кръстовиАната сграАа поА Голямата базилика през първия строителен периоА: а) (Boyadzhiev, 2008, appendix); б) (Vasilev, 2009, fig. 9); в) (Georgiev, 1993, p. 49, fig. 38 b). 


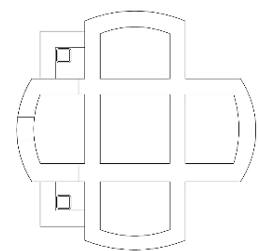

a

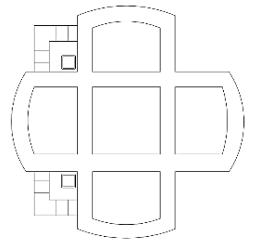

б

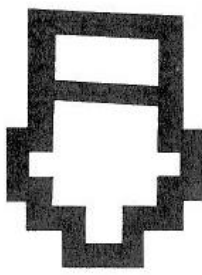

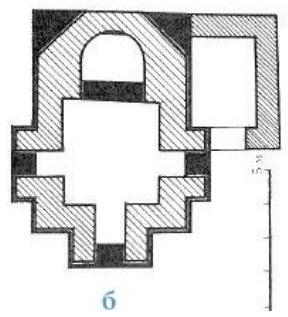

Фиг. 5 а) Първи строителен периоА на кръстовиАната сграАа - капище ?; б) Църква № 3 и гробничната пристройка (Rashev, 2008, p. 493, fig. $X L, 2,3)$. запаАното кръстно рамо; б) Аостъпът Ао басейнчетата е осъществяван чрез Аиректно вАизане в помещенията в межАурамията (по автора) 


\section{LITERATURE ( $\triangle$ UTEPATYPA)}

Beshevliev, V. (1981). The first Bulgarians. Life and Culture. [Бешевлиев, В. (1981). Първобългарите. Бит и култура].

Boyadzhiev, St. (1986). Mausoleum of the first Bulgarian khans. Museums and Monuments of Culture, 2, 28-32. [Бояджиев, Ст. (1986). Мавзолей на първите български ханове. Музеи и паметници на културата, 2, с. 28-32].

Boyadzhiev, St. (2008). Bulgarian architecture in the VII-XIV century. Pre-Christian architecture. Volume 1. [БояАжиев, Ст. (2008). Българската архитектура през VIIXIV век. Аохристиянска архитектура. Т. 1].

Chaneva-Dechevska, N. (1984). The church architecture of the First Bulgarian state. [Чанева-Аечевска, Н. (1984). Цьрковната архитектура на Пьрвата българска Аьржава].

Chobanov, T. (2014). The Pagan Temples of Danube Bulgaria. Ancient Bulgarians - the discussion continues, 66-90. [Чобанов, Т. (2014). Езическите храмове на Аунавска България. Аревните българи - Аискусията прольлжава, с. 66-90].

Doncheva-Petkova, L. (1995). Archaeological information about Christianity in Bulgaria before and immediately after baptism. 1100 Veliki Preslav, 1, 195-205. [АончеваПеткова, ^. (1995). Археологически сведения за християнството в България преди и непосредствено след покрьстването. 1100 г. Велики Преслав, 1, с. 195205].

Georgiev, P. (1993). The Martyrdom in Pliska and the beginning of Christianity in Bulgaria. [Георгиев, П. (1993). Мартириумьт в Плиска и началото на християнството в България].

Georgiev, P., St. Vitlyanov (2001). The Archbishopric - a monastery in Pliska. [Георгиев, П., Ст. ВитАянов (2001). Архиепископията - манастир в Плиска].

Hrisimov, N. (2018). Observations on the personality of Enravota and the cross-shaped building under the Great Basilica. Pliska-Preslav. 13, 81-90. [Хрисимов, Н. (2018). НаблюАения вьрху мичността на Енравота и крьстовиАната сграда поА Голямата базилика. Плиска-Преслав, 13, с. 81-90].

Milchev, А. (1995). Р. Георгиев. The Martyrdom in Pliska and the beginning of Christianity in Bulgaria (review). Archeology, 2, 52-53. [Милчев, А. (1995). П. Георгиев. Мартириумьт в Плиска и началото на християнството в Бьлгария (рецензия). Археология, 2, с. 52-53].

Mihailov, St. (1995). More about the cross-shaped building under the Great Basilica in Pliska. Archeology, 4, 47-49 [Михайлов, Ст. (1995). Още за крьстовиАната постройка пол Голямата базилика в Плиска. Археология, 4, с. 47-49].

Ovcharov, D. (2005). About the place of the tomb of Khan Omurtag - conjectures and hypotheses. Helis, IV [Овчаров, А. (2005). За мястото на гроба на хан Омуртаг АогаАки и хипотези. Хемис, IV].

Popkonstantinov, K. (2005). Once again the so-called martyrdom in Pliska. Prof. Ph.D. Stancho Vaklinov and the Medieval Bulgarian Culture, 24-32. [Попконстантинов, К. (2005). Още веднъж т. нар. мартириум в Плиска. Профо. А.И.Н. Станчо Ваклинов и средновековната българска култура, с. 24-32]. 
Rashev, R. (2008) The Bulgarian pagan culture VIIIX century. [Рашев, P. (2008). Българската езическа култура VII-IX век].

Stanilov, St. (1982). The language centers of the First Bulgarian state. Bulgaria 1300 years, 225-234. [Станилов, Ст. (1982). Езическите центрове на Първата българска Аьржава. България 1300 голини, с. 225-234].

Teofilov, T. (1993). From a temple to a church. Notices of the Museums in Northern Bulgaria, 9, 73-92. [Теофилов, Т. (1993). От капище към цьрква. Известия на музеите в Северна България, 9, с. 73-92].

Totev, T. (1984). The cross-shaped building under the foundations of the Great Basilica in Pliska (865-866). Collection in memory of Prof. St. Ваклинов, 160-170. [Тотев, Т. (1984). КрьстовиАната сграда поА основите на Голямата базилика в Плиска (865-866). Сборник в памет на профо. Ст. Ваклинов, с. 160-170].

Tsanev, Ts. (1998). On the Question of the Christianization of the Bulgarians. Preslav Literary School, 3, 159-167. [Цанев, Ц. (1998) Кьм вьпроса за покрьстването на българите. Преславска книжовна школа, 3, с. 159-167].

Vaklinov, St. (1974). Pliska for thirty years. Archeology, 3, 28-39. [ВакАинов, Ст. (1974). Плиска за тридесет години. Археология, 3, с. 28-39].

Vaklinov, St. (1977). Formation of the old Bulgarian culture VII-XI century. [ВакАинов, Ст. (1977). Формиране на старобългарската култура VII-XI век].

Vaklinov, St., I. Shtereva (1993). Studies of the Great Basilica in Pliska in 1971-1973. PliskaPreslav, 6, 33-48. [Ваклинов, Ст., И. Щерева (1993). Проучвания на Голямата базилика в Плиска през 1971-1973 г. Плиска-Преслав, 6, с. 33-48].

Vasilev, Ya. (2009). The cross-shaped building - mausoleum under the Great Basilica in Pliska (https://bazileus.eu/statii/142-krystovidna-sgrada.html ) visited: 01.03.2021. [Василев, Я. (2009). Крьстовилната сграла - мавзолей пол Голямата базилика в Плиска (https://bazileus.eu/statii/142-krystovidna-sgrada.html ) Пос^. посетен: 01.03 .2021 г.])].

GALABINA YOSIFOVA

PhD student

b8d8h8@abv.bg 

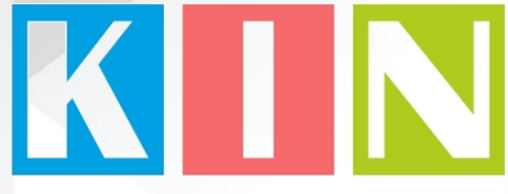

\section{ISSN: 2367-8038}

\section{Съставители \\ Петко Ст. Петков \\ Галина БогАанова}

Материалите в сборника са обект на авторско право. Разрешава се безвъзмезАното ползване на техни електронни/ хартиени копия само за мична употреба или обучение, при пьлно цитиране на текущата страница и слеА писмена Аек^арация от цитиращия за ^ипса на търговски намерения.

Научната поредица е регистрирана в НАЦИА С № 1209

() Авторски колектив, 2021

Техническо реАактори: Калина Сотирова-Вълкова Николай Ноев Паска^ Пиперков

\section{Editors}

Petko St. Petkov

Galina Bogdanova

This work is subject to copyright.

Open and free of charge use of digital/hard copies of publications is granted only for personal or educational use, with full citation of the current page, and after written declaration of the quoting side for notcommercial Intention.

Science series has been registered in NACID with No. 1209

() Authors` Group, 2021

Technical editors:

Kalina Sotirova-Valkova

Nikolay Noev

Paskal Piperkov

\section{ISSN: 2367-8038}

том 7, брой $1(10) / 2021$

vol. 7 , issue $1(10) / 2021$ 